\title{
Magnetizations of the seamounts in the Izu-Ogasawara arc with special reference to the origin of their normal polarity biases
}

\author{
Yoshio Ueda* \\ Japan Coast Guard Academy, 5-1, Wakaba-cho, Kure-shi, Hiroshima, Japan \\ (Received September 20, 2006; Revised February 27, 2007; Accepted April 4, 2007; Online published July 20, 2007)
}

\begin{abstract}
Magnetizations of the seamounts in the Izu-Ogasawara arc are calculated using correlation analyses of magnetic anomalies and topographic data. The calculated results of the seamounts in the Sitito-Iozima ridge (present volcanic front) show normal magnetizations with a mean value of $5.10 \pm 1.38 \mathrm{~A} / \mathrm{m}$. The results also show that the majority of the seamounts in the Nisi-Sitito ridge, which are Pliocene and Middle Miocene in origin, are magnetized in a normal magnetic field direction with a mean value of $2.74 \pm 1.07 \mathrm{~A} / \mathrm{m}$. Seamounts in the Kyushu-Palau ridge, which are Oligocene in origin, also show predominantly normal polarities, with a mean of $2.67 \pm 0.71 \mathrm{~A} / \mathrm{m}$. For such a polarity bias to be explained by induced magnetization components (IM), including viscous remanent magnetization (VRM), the intensity of IM should be comparable to the mean of $2.74 \mathrm{~A} / \mathrm{m}$. However, no significant differences in the standard deviations of magnetization intensities are recognized between the seamounts in the Nisi-Sitito Ridge and those in the Sitito-Iozima Ridge, contrary to expectations if the normal polarity bias is IM in origin. Three-dimensional (3-D) multi-block model analyses are also applied to 25 seamounts having magnetization directions considerably different from those of the present magnetic field to estimate the normally and reversely magnetized volumes of the seamounts. The results show that $88 \%(22 / 25)$ of the seamounts have relatively greater volumes of normal magnetization compared to reverse magnetization. The IM component estimated from the 3-D multi-block model is a maximum of $0.66 \mathrm{~A} / \mathrm{m}$, which is too small to explain the observed normal polarity bias. A possible alternative explanation for the observed normal polarity bias may be enhanced volcanic activity during normal magnetic periods, although this is difficult to justify theoretically at the present time.
\end{abstract}

Key words: Arc volcanism, magnetic anomaly, polarity bias, seamounts, paleomagnetism, Izu-Ogasawara arc, Kyushu-Palau ridge.

\section{Introduction}

It is well known that numerous seamounts and volcanic edifices in the western to central Pacific basin were generated during the Cretaceous normal superchron. This has been confirmed from the fact that the majority of seamounts are magnetized in the normal magnetic direction (Francheteau et al., 1970; Harrison et al., 1975; Hildebrand and Staudigel, 1986; Sager, 1992). This enormous igneous activity is ascribed to a mantle plume resulting from high heat flux at the core-mantle boundary in the magnetic normal period. Moberly and Campbell (1984) also pointed out that the majority of the volcanic seamounts formed at the Hawaiian hotspot have normal magnetizations, and they attributed this polarity bias to the high heat flux at the coremantle boundary during the magnetic normal period. The reversely magnetized lavas in the Emperor chain were recovered thereafter (Tarduno et al., 2003), however, the overall normal polarity bias itself has not been disproved. On the other hand, Merrill (1985) and Verhoef and Collette

\footnotetext{
*Now at Japan Hydrographic Association, 5-3-3, Tsukiji, Chuo-ku, Tokyo, Japan.

Copyright (c) The Society of Geomagnetism and Earth, Planetary and Space Sciences (SGEPSS); The Seismological Society of Japan; The Volcanological Society of Japan; The Geodetic Society of Japan; The Japanese Society for Planetary Sciences; TERRAPUB
}

(1985) raised objections to the view presented by Moberly and Campbell (1984), insisting on a viscous remanent magnetization (VRM) origin of the polarity bias. In the present study, a magnetic polarity bias in island arc volcanism was examined for the Izu-Ogasawara arc and the Kyushu-Palau ridge (KPR). These results suggest a close relation between an arc volcanism in the subducting zone and magnetic normal polarity periods.

\section{Geological Background}

The Izu-Ogasawara arc is characterized by three alongarc volcanic zones: the central one, called the Sitito-Iozima ridge (SIR), corresponding to the Quaternary volcanic front; the eastern ridge, called the Ogasawara ridge (OGR) of the Eocene age (Tsunakawa, 1983); the westernmost zone, called the Nisi-Sitito ridge (NSR), is the old volcanic zone, ranging in age between the Pliocene and Middle Miocene (Yuasa and Murakami, 1985; Katsura et al., 1994; Ishizuka et al., 1998). There are numerous seamounts and active volcanoes along the SIR and NSR, as shown in Fig. 1. Magnetic anomalies on these seamounts are mainly characterized by dipole type anomalies, suggesting normal magnetizations (Yamazaki et al., 1991; Ueda, 1996). The seamounts in the KPR also show predominant normal magnetizations, and to date no reversely polarized seamount has been discovered (Ueda, 2004). The KPR is thought 


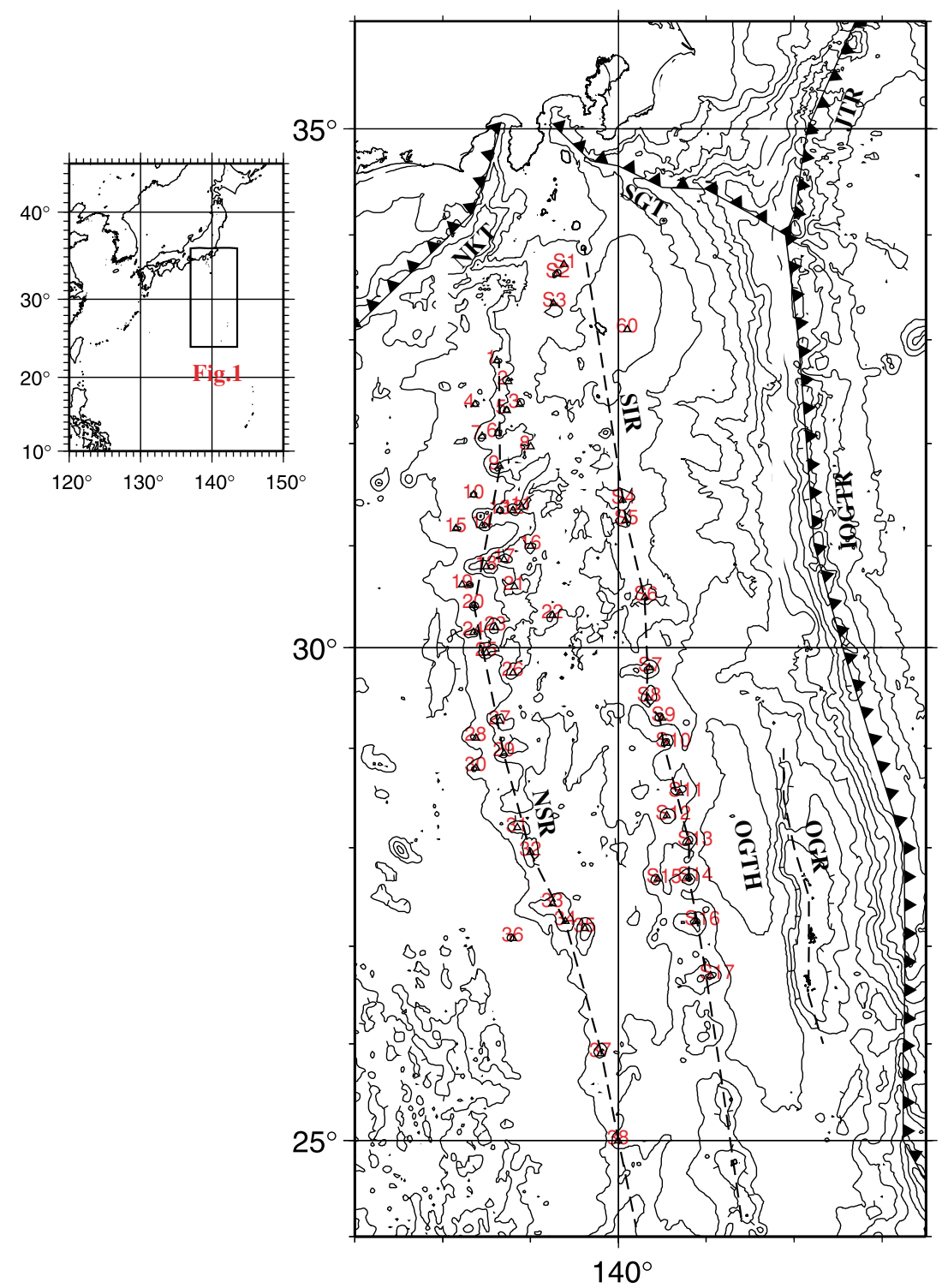

Fig. 1. Bathymetric map of the Izu-Ogasawara arc and surrounding geological zones. Locations of seamounts analyzed in the present study are shown by identification numbers (ID). Three broken lines show along arc geological zones of Sitito-Iozima ridge (SIR), Nisi-Sitito ridge (NSR), and Ogasawara ridge (OGR), respectively. Trenches are shown by lines of solid triangles. JTR, Japan trench; IOGTR, Izu-Ogasawara trench; SGT, Sagami trough; NKT, Nankai trough.

to be generated prior to the opening of the Shikoku basin at approximately $25 \mathrm{Ma}$ (Tomoda et al., 1975; Okino et al., 1994). Hornblende dacites sampled from the KitaKoho seamount $\left(26.77^{\circ} \mathrm{N}, 135.46^{\circ} \mathrm{E}\right)$ were determined to be $25 \sim 26 \mathrm{Ma}$ of age using the K-Ar method (Katsura et al., 1994). Magnetic polarity intervals in the late Oligocene to Early Miocene are also characterized by short durations. The above features, suggesting polarity bias in the arc volcanism, are serious issues for understanding the magnetizations of these edifices and their origins.

\section{Data and Method of Analysis \\ 3.1 Data}

The geophysical data used for this study are mainly based on survey results observed by the survey vessels of the Hydrographic and Oceanographic Department of Japan (HOD). In these surveys, the track lines were at intervals of about 2-5 nautical miles (Ueda, 1996). The survey data are depth sounding, seismic profiling, and magnetic and gravity measurements. Depth sounding data were collected both by a single beam echo sounder and by a sea-beam system. Geophysical data have revealed detailed magnetic and topographic features over the Shikoku basin, Izu-Ogasawara arc, and the Ryukyu Islands (Kasuga et al., 1994; Ueda, 1996). Magnetic anomalies were calculated based on the IGRF 1985 model and then converted to $1 \times 1-\mathrm{km}$ grid data using the minimum curvature algorithm (Smith and Wessel, 1990) (Fig. 2). Topographic data are also converted into the same grid. The locations of seamounts analyzed are shown by the ID numbers in Fig. 1 .

\subsection{Correlation analysis of magnetic anomalies}

To estimate the magnetization of three-dimensional (3-D) edifices, a correlation method using direct searching algorithm was used on the assumption of uniform magnetization of a source body. This method is effective for rapid estimations of magnetizations of edifices in the absence of polyg- 


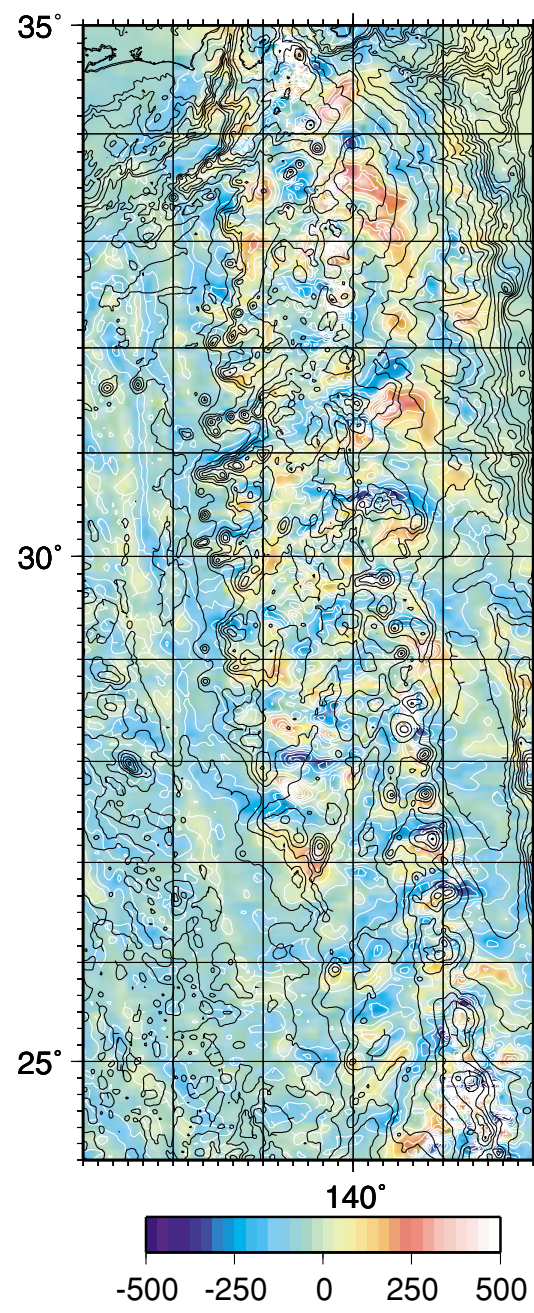

(a)

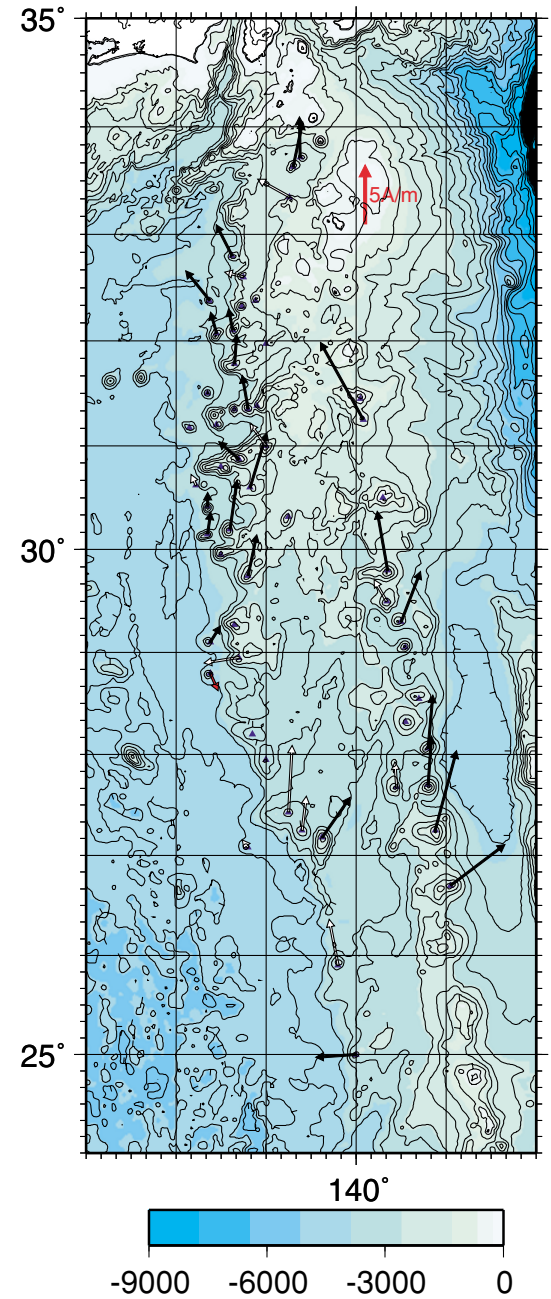

(b)

Fig. 2. Magnetic anomalies and derived horizontal magnetization vectors of seamounts in the Izu-Ogasawara arc. Magnetization vectors of seamounts with GFR $\geqq 2.5$ are plotted in Fig. 2(b). (a) Total intensity magnetic anomalies. (b) Horizontal magnetization vectors of seamounts in the Izu-Ogasawara arc.

onal models of topographic edifices (Ueda, 2004). When the topographic mesh data are given, the magnetic anomalies caused by the topographic model can be calculated using a 3-D inversion in the frequency domain, under the given directions of the magnetization field and the polarization of the magnetization of the edifices. By changing the magnetization directions every $1^{\circ}$, We can find a magnetization direction giving the maximum goodness-of fitratios (GFR) and other relevant precision parameters. In the present study, results are evaluated using a standard deviation $(\sigma)$, correlation parameter (Cor) and GFR parameters (Uyeda and Richards, 1966):

$$
\begin{aligned}
& \sigma=\sum_{i=1}^{N X} \sum_{j=1}^{N Y}\left(\mathrm{Obs}_{i, j}-\mathrm{Cal}_{i, j}\right)^{2} / N \\
& \mathrm{GFR}=\sum_{i=1}^{N X} \sum_{j=1}^{N Y}\left|\mathrm{Obj}_{i, j}\right| / \sum_{i=1}^{N X} \sum_{j=1}^{N Y}\left|\mathrm{Obj}_{i, j}-\mathrm{Cal}_{i, j}\right| \\
& \mathrm{Cor}=\sum_{i=1}^{N X} \sum_{j=1}^{N Y} \mathrm{Cal}_{i, j} \cdot \mathrm{Obs}_{i, j} /\left[\sum_{i=1}^{N X} \sum_{j=1}^{N Y} \mathrm{Cal}_{i, j}^{2} \cdot \mathrm{Obs}_{i, j}^{2}\right]^{\frac{1}{2}}
\end{aligned}
$$

where, $N=N Y \times N X$, and suffix $i, j$ indicates the grid point. Obs and $\mathrm{Cal}$ are the observed and calculated anomalies, respectively.

The magnetization intensity $\left(J_{r}\right)$ is calculated after Grauch (1987) as:

$$
J_{r}=\left(\sum \sum \mathrm{Obs}_{i, j} \cdot \mathrm{Cal}_{i, j} / \sum \sum \mathrm{Cal}_{i, j}^{2}\right) \cdot J_{0}
$$

where, $J_{0}$ is an assumed magnetization intensity used for the calculation of anomalies.

Figure 3 shows an example of a result calculated from the Kanpo seamount (ID-19). This figure indicates that the magnetization intensity calculated by the correlation method is relatively stable for the change of declination angles but sensitive to the change of an inclination angle (about $0.15 \mathrm{~A} / \mathrm{m}$ for $10^{\circ}$ ). This characteristic may arise from the fact that the amplitude of a calculated anomaly is mainly dependent on an inclination of magnetization, rather than declination. 


\section{SGM}

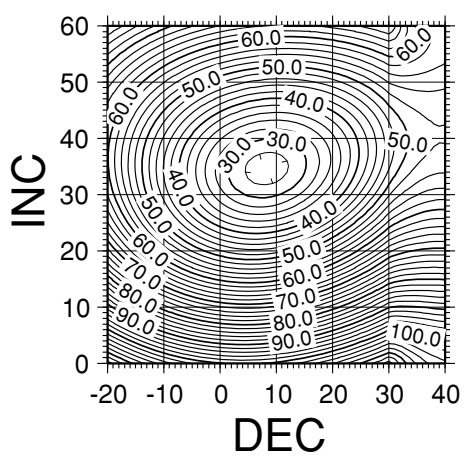

GFR

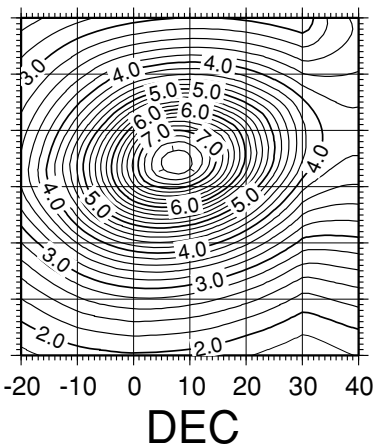

$\mathrm{J}(\mathrm{A} / \mathrm{m})$

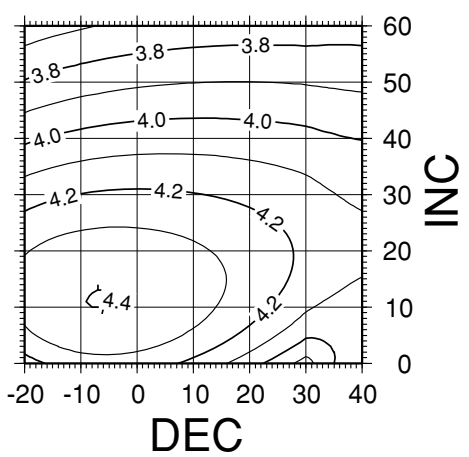

Fig. 3. An example of the correlation analysis of Kanpo seamount (19) Horizontal axis corresponds to declination angles and the vertical axis to inclinations of assumed magnetization vectors. SGM: Standard deviations of misfits between observed and calculated anomalies, GFR: Goodbess of fitting ratio, $J$ : magnetization intensity in $\mathrm{A} / \mathrm{m}$ units.

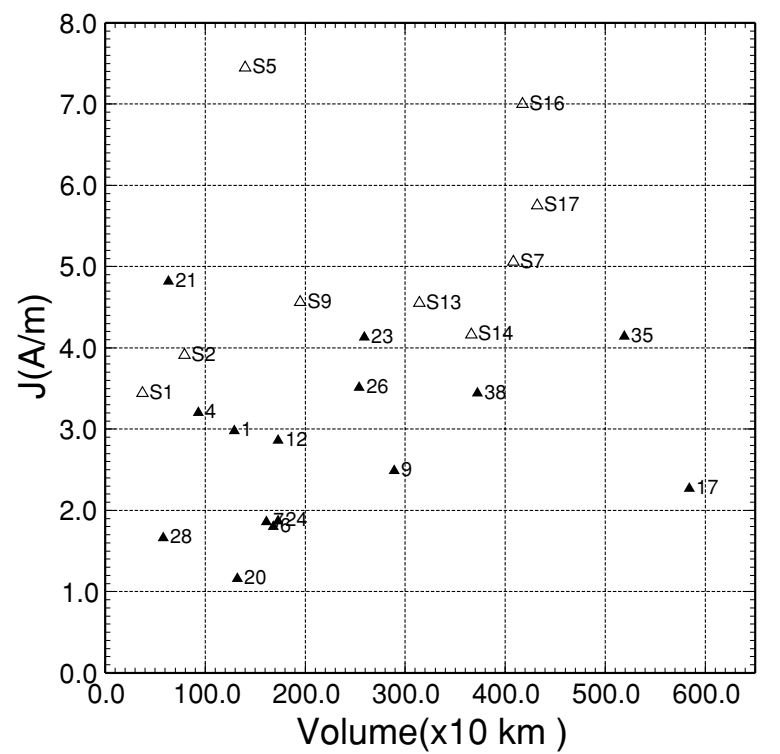

Fig. 4. Relation between magnetization intensities and volumes of the seamounts analyzed by the correlation method. The results (GFR $\geqq 2.5)$ are plotted. Solid triangles are seamounts in NSR and open triangles are those in SIR. The numbers are also shown in Tables 1 and 2. Correlation coefficients are 0.25 for NSR, and 0.36 for SIR, respectively.

\subsection{A 3-D multi-block modeling for non-uniform mag- netization analysis}

In the correlation analysis, the seamount is assumed to be magnetized uniformly throughout the edifice. This uniform magnetization assumption is thought to be acceptable in first-order approximations when the derived GFR is greater than about 2.0 (Sager, 1987). The result, with GFR = 2.0, tentatively means that calculated anomalies represent onehalf of the observed anomalies; in other words, residuals still remain as much as half of observed field values. Residual anomalies are mainly caused by inhomogeneous magnetizations of the edifice arising from field reversals and magma compositional differences (Gee et al., 1988). To reduce residual anomalies, a 3-D multi-block modeling method (Ueda, 2006) is applied to those seamounts having unusual magnetization directions to elucidate the non- uniform magnetization structures and to estimate the normal and reverse magnetization volumes of the seamounts.

The present 3-D multi-block modeling method approximates an edifice by an assemblage of prismatic bodies having variable magnetization intensities with the same magnetization direction. I define the observed anomaly vector $\mathbf{Y}\left(y_{i}, i=1, M\right)$ and magnetization intensity vector $\mathbf{J}\left(J_{k}\right.$, $k=1, N)$, where $M$ is the observation number, and $N$ is the block number of the stacking prism. Then, vector $\mathbf{Y}$ can be related to vector $\mathbf{J}$ by a Jacobian matrix $\mathbf{H}(M \times N)$ as

$$
\mathbf{Y}=\mathbf{H} \cdot \mathbf{J}
$$

where the element of $H(i, k)$ is a magnetic anomaly of total force at the point $i$ due to the unit magnetization intensity of the $k$-th block.

In this analysis, the base depths of the seamounts are unknown, but they are extended until the GFR becomes greater than 5.0. To solve the above equation, a refined CG method (Bjorck and Elfving, 1979) is used, because of its fast convergence and flexibility for solving large matrices $(1000 \times 1000$ and larger). From the derived vector $\mathbf{J}$ and the block volumes, a mean magnetization intensity averaged by the weight of the volume is calculated, and the volume rates of the normal magnetization parts $(J \geqq 0)$ against the total volume of the blocks are calculated.

\subsection{Correlation analysis of gravity anomalies}

To estimate a density of a 3-D volcanic edifice, a correlation analysis between free-air gravity anomalies and the calculated anomalies by topographic undulations was conducted. Based on 2-D topographic data, gravity values $(g)$ at the grid points can be calculated from the Fourier transform of gravity fields assuming a uniform density contrast $\rho$ as follows (Richard, 1995):

$$
\Re(g)=2 \pi \rho G_{c} \cdot \exp \left(-k z_{0}\right) \cdot \sum_{n=1}^{\infty} \frac{(-k)^{n-1}}{n !} \cdot \Re\left(z^{n}\right)
$$

where, $\Re(g)$ is a Fourier transform of a 2-D function of $g, G_{c}$ is Newton's gravitational constant, $k=\sqrt{k_{x}^{2}+k_{y}^{2}}$, $k_{x}=\frac{2 \pi}{\lambda_{x}}, k_{y}=\frac{2 \pi}{\lambda_{y}}$, and $\lambda_{x}, \lambda_{y}$ mean wavelengths in the 
Table 1. Magnetizations of seamounts in NSR with related informations.

\begin{tabular}{|c|c|c|c|c|c|c|c|c|c|c|c|c|}
\hline ID & $\begin{array}{l}\text { Lat } \\
\left({ }^{\circ}\right)\end{array}$ & $\begin{array}{c}\text { Lon } \\
\left({ }^{\circ}\right)\end{array}$ & $\begin{array}{c}J \\
(\mathrm{~A} / \mathrm{m})\end{array}$ & $\begin{array}{l}D_{r} \\
\left({ }^{\circ}\right)\end{array}$ & $\begin{array}{l}I_{r} \\
\left(^{\circ}\right)\end{array}$ & Corr & GFR & $\begin{array}{r}\text { Vol } \\
\mathrm{km}^{3}\end{array}$ & $\begin{array}{c}\rho \\
\mathrm{g} / \mathrm{cm}^{3}\end{array}$ & Name & Age & Samples*1 \\
\hline 1 & 32.8 & 138.62 & 2.98 & -7 & 47 & 0.94 & 3.16 & 129 & 2.10 & Keityo & & \\
\hline 2 & 32.6 & 138.75 & 1.63 & -76 & 30 & 0.84 & 2.27 & 148 & 2.42 & Genna & & \\
\hline 3 & 32.38 & 138.88 & 0.71 & 99 & 50 & 0.61 & 1.21 & 190 & 2.51 & Kanei & & \\
\hline 4 & 32.38 & 138.37 & 3.20 & -39 & 9 & 0.95 & 3.26 & 93 & $*$ & Nisi-seiho & & \\
\hline 5 & 32.32 & 138.73 & 1.60 & 40 & 15 & 0.81 & 1.71 & 127 & 2.48 & Seiho & & \\
\hline 6 & 32.1 & 138.63 & 1.80 & -11 & 48 & 0.94 & 3.32 & 168 & 2.52 & Syouou & & \\
\hline 7 & 32.07 & 138.45 & 1.86 & -16 & 58 & 0.91 & 2.57 & 161 & 2.33 & Nisi-syouou & & \\
\hline 8 & 31.97 & 139.00 & -1.33 & -30 & 6 & -0.68 & 1.50 & 75 & $*$ & Meireki & $3.76 \mathrm{Ma}$, & $\mathrm{d}, 2$ \\
\hline 9 & 31.78 & 138.65 & 2.49 & 4 & 42 & 0.93 & 3.01 & 289 & 2.66 & Kanbun & $8.89 \mathrm{Ma}$ & $\mathrm{a}, 2$ \\
\hline 10 & 31.50 & 138.35 & 1.20 & -16 & -21 & 0.83 & 1.81 & 107 & $*$ & Kita-Jyokyo & & \\
\hline 11 & 31.38 & 138.9 & 1.39 & -50 & 47 & 0.66 & 1.50 & 229 & 2.44 & Enpo & $1.49 \mathrm{Ma}$, & $\mathrm{b}, 2$ \\
\hline 12 & 31.35 & 138.8 & 2.86 & -10 & 15 & 0.97 & 4.55 & 173 & 2.64 & Ten'na & $4.54 \mathrm{Ma}$, & $\mathrm{a}, 2$ \\
\hline 13 & 31.35 & 138.65 & 1.78 & -65 & -32 & 0.84 & 1.95 & 156 & 2.67 & Jyokyo & & \\
\hline 14 & 31.2 & 138.45 & 2.56 & -44 & 20 & 0.69 & 1.57 & 90 & 2.99 & Nisi-Jyokyo & $3.65 \mathrm{Ma}$, & $\mathrm{b}, 2$ \\
\hline 15 & 31.17 & 138.15 & 1.60 & -67 & -7 & 0.78 & 1.43 & 70 & $*$ & Oki-Jyokyo & & \\
\hline 16 & 31.0 & 139.0 & 2.34 & -36 & 54 & 0.86 & 2.34 & 329 & 2.72 & Genroku & $1.53-5.11 \mathrm{Ma}$ & $\mathrm{b}, 2$ \\
\hline 17 & 30.87 & 138.7 & 2.27 & -49 & 27 & 0.95 & 3.52 & 584 & 2.50 & Houei & & \\
\hline 18 & 30.8 & 138.50 & 1.46 & -72 & 31 & 0.85 & 1.97 & 256 & 2.66 & Syotoku & $2.95-6.75 \mathrm{Ma}$ & $\mathrm{a}, \mathrm{d}, 2$ \\
\hline 19 & 30.62 & 138.22 & 1.01 & -25 & 47 & 0.91 & 2.32 & 63 & $*$ & Kyoho & $4.82 \mathrm{Ma}$, & $\mathrm{a}, 2$ \\
\hline 20 & 30.42 & 138.35 & 1.16 & 0 & 43 & 0.99 & 6.69 & 132 & 2.53 & Genbun & & \\
\hline 21 & 30.6 & 138.82 & 4.82 & 17 & 29 & 0.93 & 3.00 & 63 & 2.87 & unnamed & $12.5 \mathrm{Ma}$ & $\mathrm{a}, 2$ \\
\hline 22 & 30.32 & 139.25 & 3.02 & 32 & 41 & 0.83 & 1.78 & 188 & 2.97 & Houreki & $3.0-3.6 \mathrm{Ma}$, & b, 3 \\
\hline 23 & 30.2 & 138.6 & 4.13 & 8 & 35 & 0.99 & 7.71 & 259 & 2.42 & Kanpo & & \\
\hline 24 & 30.15 & 138.35 & 1.87 & 8 & 42 & 0.95 & 3.50 & 173 & 2.46 & Enkyo & & \\
\hline 25 & 29.95 & 138.5 & -2.54 & 64 & -50 & -0.86 & 2.13 & 399 & 2.85 & Kanen & & \\
\hline 26 & 29.75 & 138.8 & 3.51 & 12 & 47 & 0.97 & 4.68 & 254 & 2.56 & Meiwa & & \\
\hline 27 & 29.27 & 138.65 & 1.52 & -2 & 30 & 0.83 & 1.99 & 336 & 2.50 & Anei & $6.33 \mathrm{Ma}$ & $\mathrm{b}, 1$ \\
\hline 28 & 29.1 & 138.38 & 1.66 & 32 & 7 & 0.91 & 2.55 & 58 & $*$ & Kansei & & \\
\hline 29 & 28.95 & 138.7 & 3.00 & -99 & 8 & 0.87 & 2.17 & 242 & 2.34 & Minami-anei & & \\
\hline 30 & 28.8 & 138.38 & -1.65 & -24 & 44 & -0.95 & 3.43 & 51 & $*$ & Minami-kansei & & \\
\hline 31 & 28.2 & 138.85 & 2.60 & -53 & 20 & 0.83 & 1.64 & 320 & 2.39 & Kyouwa & & \\
\hline 32 & 27.95 & 139.0 & 2.55 & -3 & 65 & 0.61 & 1.34 & 447 & 2.20 & Bunka & & \\
\hline 33 & 27.43 & 139.25 & 5.65 & 3 & 30 & 0.86 & 2.20 & 295 & $*$ & Bunsei & & \\
\hline 34 & 27.25 & 139.4 & 2.94 & 7 & 44 & 0.87 & 2.13 & 183 & 2.46 & Nisi-tenpo & & \\
\hline 35 & 27.18 & 139.62 & 4.14 & 35 & 41 & 0.91 & 2.65 & 519 & 2.69 & Tenpo & 11.6-15.3 Ma, & $\mathrm{a}, \mathrm{b}, 1$ \\
\hline 36 & 27.08 & 138.8 & 0.79 & -38 & -40 & 0.90 & 2.15 & 96 & $*$ & Kouka & & \\
\hline 37 & 25.9 & 139.8 & 3.99 & -11 & 62 & 0.90 & 2.45 & 238 & 2.65 & Nisi-kaitoku & & \\
\hline 38 & 25.0 & 140.0 & 3.44 & -94 & 57 & 0.96 & 4.07 & 372 & 2.35 & unnamed & & \\
\hline
\end{tabular}

${ }^{* 1}$ : Age in Ma, b: basalt, a: andesite, d: dacite,

1: Katsura et al. (1994), 2: Ishizuka et al. (1998), 3: Shukuno et al. (2006).

horizontal plane, $z_{0}$ is mean depth, and $z$ is the height from $z_{0}$.

Gravity fields caused by 2-D topographic undulations can be calculated from the inverse transform of $\Re(g)$. Then, by correlating observed and calculated gravity anomalies, we can estimate a mean density contrast from the amplitude factor of Eq. (2) by replacing $J_{0}$ to unit density. The derived mean density contrasts satisfying the condition GFR $\geqq 2.5$ are shown in the far-right rows in Tables 1 and 2 . In the present calculations, free-air gravity anomalies compiled by Ueda (2005) were used.

\section{Results of the Calculations}

\subsection{Results of the correlation analysis}

The results obtained by the correlation method are listed in Table 1 for seamounts in the NSR and in Table 2 for those in the SIR, respectively. In the following discussions, a se- lection criterion of GFR $\geq 2.5$ is adopted, which is stricter than the criterion of GFR $\geqq 2.0$. Twenty-five seamounts remain following the removal of those results having low GFR $(<2.5)$. Magnetization vectors of the seamounts are indicated in Fig. 2(b) with a colored magnetic anomaly map used for the analyses (Fig. 2(a)). In terms of the results calculated for the seamounts in SIR, nine seamounts show reliable results (GFR $\geqq 2.5$ ). Among them, six are magnetized in the normal direction and the remaining three have magnetizations significantly deflected from the present direction. These deflections may be attributable to non-uniform magnetizations. As described above, no seamounts showing unequivocally reversed magnetization were recognizable from the seamounts in the SIR.

With respect to the seamounts in the NSR, 16 seamounts show reliable results (GFR $\geqq 2.5$ ). Among them, 11 (1, $6,7,9,12,20,21,23,24,26,35)$ are normally magne- 
Table 2. Magnetizations of seamounts in SIR.

\begin{tabular}{|c|c|c|c|c|c|c|c|c|c|c|}
\hline ID & $\begin{array}{l}\text { Lat } \\
\left({ }^{\circ}\right)\end{array}$ & $\begin{array}{l}\text { Lon } \\
\left(^{\circ}\right)\end{array}$ & $\begin{array}{c}J \\
(\mathrm{~A} / \mathrm{m})\end{array}$ & $\begin{array}{l}D_{r} \\
\left(^{\circ}\right)\end{array}$ & $\begin{array}{l}I_{r} \\
\left(^{\circ}\right)\end{array}$ & Corr & GFR & $\begin{array}{r}\text { Vol } \\
\mathrm{km}^{3}\end{array}$ & $\begin{array}{c}\rho \\
\mathrm{g} / \mathrm{cm}^{3}\end{array}$ & Name \\
\hline S1 & 33.72 & 139.38 & 3.44 & -1 & 40 & 0.98 & 5.63 & 37 & 2.54 & Mikura \\
\hline $\mathrm{S} 2$ & 33.63 & 139.3 & 3.91 & 12 & 32 & 0.94 & 3.03 & 79 & 2.60 & Inanba \\
\hline $\mathrm{S} 3$ & 33.35 & 139.26 & 3.1 & -61 & 75 & 0.91 & 2.48 & 138 & 2.62 & Unnamed \\
\hline S4 & 31.45 & 140.05 & 3.07 & -50 & 57 & 0.83 & 1.74 & 380 & 2.66 & Sumisu \\
\hline S5 & 31.25 & 140.08 & 7.45 & -29 & -23 & 0.93 & 2.73 & 140 & $*$ & Minami-sumisu \\
\hline S6 & 30.5 & 140.3 & 3.87 & -1 & 46 & 0.66 & 1.38 & 439 & $*$ & Torisima \\
\hline S7 & 29.8 & 140.35 & 5.06 & -10 & 40 & 0.95 & 4.00 & 408 & 3.03 & Sofu \\
\hline S8 & 29.5 & 140.34 & 2.1 & -30 & -1 & 0.89 & 2.26 & 273 & 2.43 & Nitiyo \\
\hline S9 & 29.3 & 140.5 & 4.56 & 21 & 29 & 0.97 & 5.18 & 195 & $*$ & 3Getuyo \\
\hline $\mathrm{S} 10$ & 29.05 & 140.55 & 2.59 & 35 & 70 & 0.86 & 1.99 & 215 & 3.11 & Кауо \\
\hline $\mathrm{S} 11$ & 28.55 & 140.7 & 10.32 & 103 & -2 & 0.56 & 1.21 & 173 & $*$ & Suiyo \\
\hline $\mathrm{S} 12$ & 28.32 & 140.55 & 2.72 & 87 & 31 & 0.30 & 1.05 & 376 & 2.88 & Mokuyo \\
\hline $\mathrm{S} 13$ & 28.06 & 140.8 & 4.55 & 5 & 32 & 0.96 & 3.77 & 314 & 3.14 & Kinyo \\
\hline $\mathrm{S} 14$ & 27.7 & 140.8 & 4.16 & 4 & 44 & 0.93 & 2.96 & 366 & 3.04 & Doyo \\
\hline $\mathrm{S} 15$ & 27.68 & 140.45 & 2.1 & -4 & 60 & 0.86 & 2.17 & 203 & 3.05 & Sawa \\
\hline S16 & 27.25 & 140.88 & 7.0 & 15 & 49 & 0.95 & 3.48 & 417 & $*$ & Nisinosima \\
\hline S17 & 26.7 & 141.05 & 5.75 & 53 & 37 & 0.91 & 2.54 & 432 & $*$ & Kaikata \\
\hline
\end{tabular}

tized, and four $(4,17,28,38)$ are magnetized in a direction significantly different from the present magnetic field direction; in addition, one seamount (30) shows a reversed magnetization. Excluding the four seamounts having large ambiguities for polarity judgment, the rate of normal magnetization is $11 / 12(92 \%)$. The predominant normal magnetization of the seamounts in the SIR is consistent with their formation during the Brunhes normal magnetic epoch. However, the predominant normal magnetization as seen in NSR is inconsistent with its formation during the Miocene to Pliocene, a period containing frequent changes in magnetic polarity. If the construction time of an edifice spans several magnetic polarities, the mean magnetization intensity may be decreased through the averaging of the normal and reversal magnetizations. If such a mixing effect were to have occurred, magnetizations of the seamounts might show reverse-correlation to their volumes because a volumetric seamount generally has a longer life-span than a small seamount.

To examine this mixing effect, magnetization intensities are plotted against the volumes of the seamounts (Fig. 4). The correlation between the magnetization intensities and volumes was calculated to be 0.25 for seamounts in the NSR, suggesting the absence of any significant reverse-correlation. Conversely, small volumetric seamounts $\left(<150 \mathrm{~km}^{3}\right)$ tend to have weak magnetization intensities $(J<2.0 \mathrm{~A} / \mathrm{m})$. The active volcanic islands of the Nisinosima and Kaikata seamounts have large volumes of over $400 \mathrm{~km}^{3}$; however, these edifices also have relatively large magnetization intensities.

\subsection{Magnetization structures of volcanic edifices by the 3D-multi-block modeling}

The results of the correlation analyses reveal that some volcanic edifices in the NSR have low GFR values of less than 2.0 and unusual magnetization directions. These results may arise from non-uniform magnetizations of the ed- ifices. Here the results of 3-D-multi-block modeling for some of the seamounts are to be shown with the aim of elucidating the origin of these unusual magnetizations.

4.2.1 Jyokyo seamount (11) From the seamounts located on the same ridge, the Nishi-Jyokyo and Ten'na seamounts, Basaltic and andesitic rocks showing an age of 3.65 Ma and 4.54 Ma, were sampled respectively (Ishizuka et al., 1998). The correlation analysis of the Jyokyo seamount shows a small GFR of 1.95 with a magnetization vector considerably different from the present field direction $\left(D_{r}=-65^{\circ}, I_{r}=-32^{\circ}\right)$. Topography and magnetic anomaly maps are shown in Fig. 5(a). The derived 3-D magnetization structure (Fig. 5(b)) shows that the volume having reverse magnetization amounts to $47 \%$. The abnormal magnetization direction obtained in the uniform model may be attributable to the mixing effect of the magnetized parts with different polarities. The mean magnetization intensity of the reverse polarity is calculated to be $1.40 \mathrm{~A} / \mathrm{m}$, and that of the normal polarity becomes $2.38 \mathrm{~A} / \mathrm{m}$. This difference may be attributable to VRM.

4.2.2 Genroku seamount (16) Mainly basaltic rocks and one dacite rock were sampled from this seamount, the ages of which range from 1.53 to $5.11 \mathrm{Ma}$ (Ishizuka et al., 1998), during which time several reversals might have occurred. The correlation analysis of the Genroku seamount shows a GFR of 2.59; however, the magnetization direction is deflected in a far westerly direction, as indicated by a declination of $-85^{\circ}$, and it is inclined deeply, as shown by inclination angle of $69^{\circ}$. Topography and magnetic anomaly maps are shown in Fig. 6(a). The derived 3-D magnetization structure (Fig. 6(b)) shows that the majority of the volcanic edifice is magnetized in the normal direction with variable magnetization intensities. This result explains the unusual magnetization direction by the non-uniformity of the magnetization intensities of the edifice. The calculated volume of normal magnetization parts amounts to $93 \%$. 
TOPO

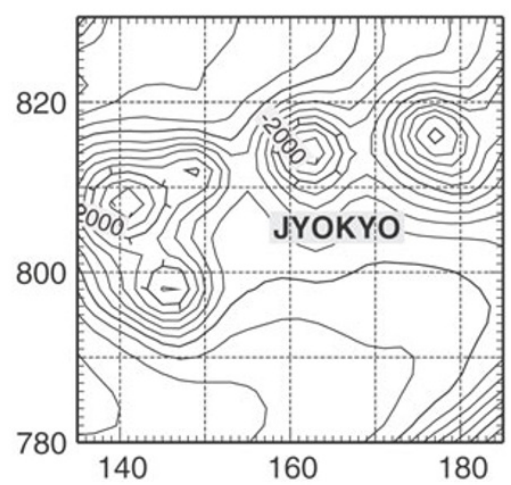

MAG

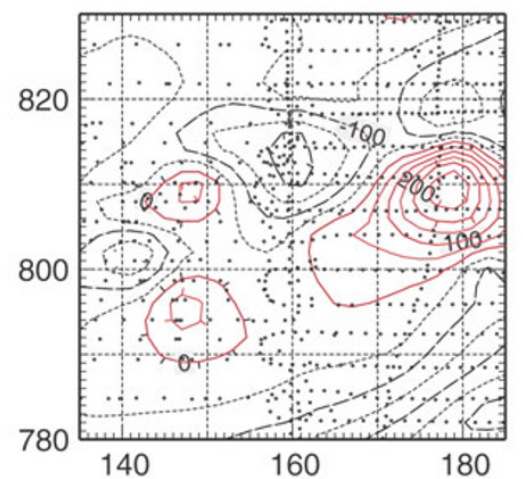

(a)

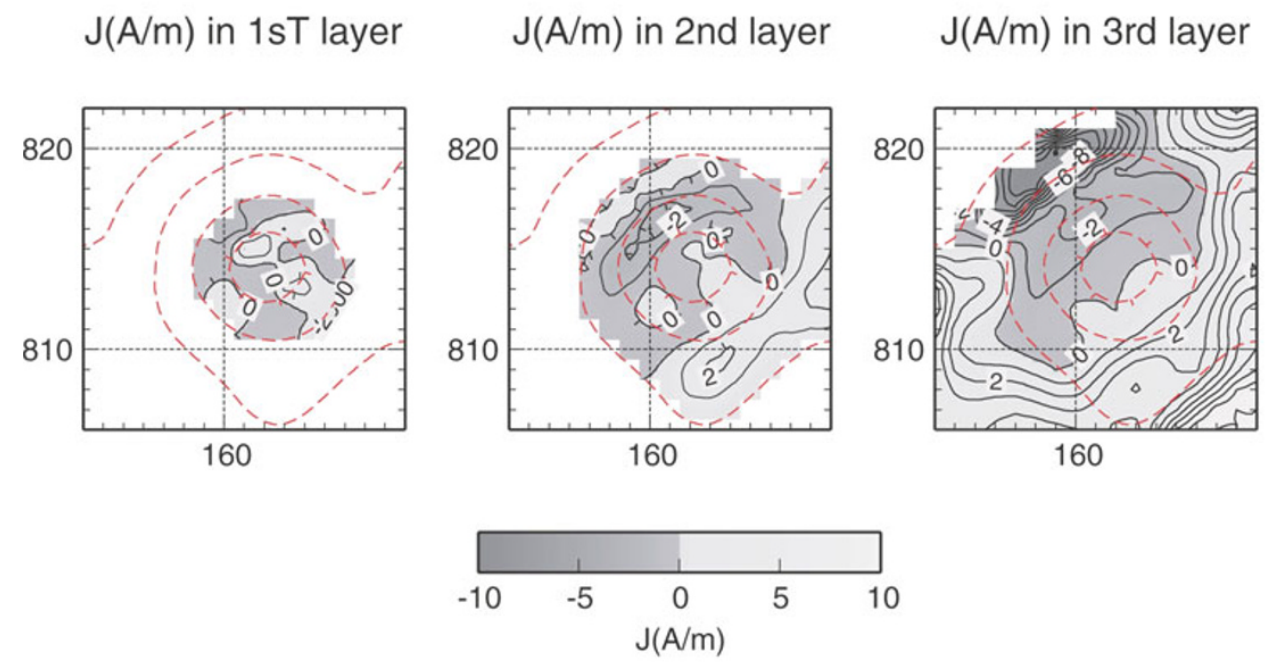

(b)

Fig. 5. Three-dimensional (3D)-multi block modeling of Jyokyo seamount. Horizontal and vertical axes show the distances in kilometers from the origin of $\left(\mathrm{N} 24.0^{\circ}, \mathrm{E} 137.0^{\circ}\right)$, respectively. (a) Topography (left) and total force magnetic anomalies (right) for Jyokyo seamounts. Observed data points are shown by dot marks. Contour interval is $200 \mathrm{~m}$ in topography and $50 \mathrm{nT}$ on the magnetic anomaly map. (b) Magnetization structure of the Jyokyo seamount derived from 3-D-multi-block modeling. Contour interval is $1 \mathrm{~A} / \mathrm{m}$. Topography is shown by broken lines at $500-\mathrm{m}$ depth intervals. Left - The first layer: 0 2000 m in depth; middle - the second layer: $2000 \sim 2500 \mathrm{~m}$ in depth; right - the third layer: $2500 \sim 3000 \mathrm{~m}$ in depth.

4.2.3 Houreki seamount (20) Basalts to andesitic basalts were sampled from this seamount, the Ar-Ar ages of which range from 3.0 to 3.6 Ma (Shukuno et al., 2006). Yet younger rocks $(0.5 \mathrm{Ma} \sim 2.9 \mathrm{Ma})$ were also recovered from the flank cones. The correlation analysis of the Houreki seamount shows a small GFR of 1.78, with an easterly deflected declination of $32^{\circ}$. The topography and magnetic anomaly maps are shown in Fig. 7(a). The derived 3-D magnetization structure (Fig. 7(b)) shows that the easterly deflected magnetization derived under the uniform magnetization assumption is caused by the non-uniformity of the magnetization intensity within the edifice. The volume of normal magnetization amounts to $89 \%$ with a mean normal magnetization intensity of $2.17 \mathrm{~A} / \mathrm{m}$, which is somewhat smaller than that obtained in the uniform model.

4.2.4 Tenpo seamount (30) Andesites and basaltic rocks were sampled from this seamount, the K-Ar ages of which range from 11.6 to $15.3 \mathrm{Ma}$ (Katsura et al., 1994). The topographic and magnetic anomalies are shown with track lines in Fig. 8(a). The derived 3-D magnetization structure (Fig. 8(b)) implies that the majority of the edifice is magnetized in the normal direction and that the strongly magnetized part $(J>10.0 \mathrm{~A} / \mathrm{m})$ is located beneath the western edifice between a depth of 2700 and $3500 \mathrm{~m}$. The easterly deflected magnetization derived from the uniform magnetization model may be caused by the non-uniform magnetization intensities of the edifice. The normal magnetization part amounts to $94 \%$. The volume of the Tenpo seamount ranges from $519 \mathrm{~km}^{3}$ (base depth $=3000 \mathrm{~m}$ ) in the lowest estimation to $990 \mathrm{~km}^{3}$ (base depth $=3600 \mathrm{~m}$ ). The construction time ranges from 0.1 to $0.3 \mathrm{Ma}$, corresponding to the plausible magma production rates (Nakamura, 1974). However, the derived results insist that the Tenpo seamount is almost magnetized in the normal direc- 
TOPO

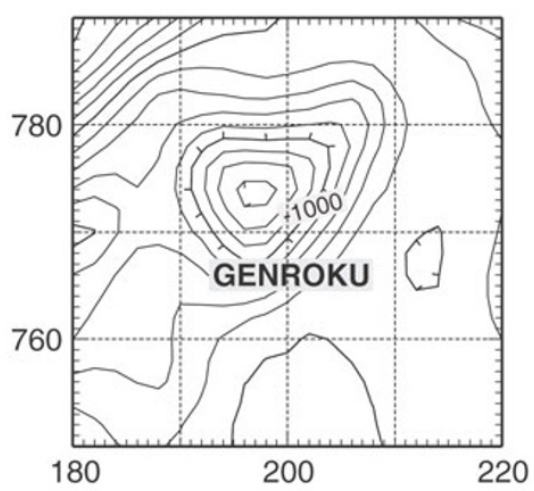

MAG

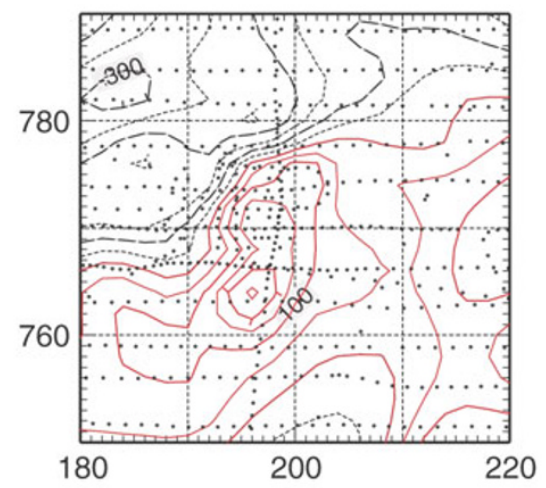

(a)

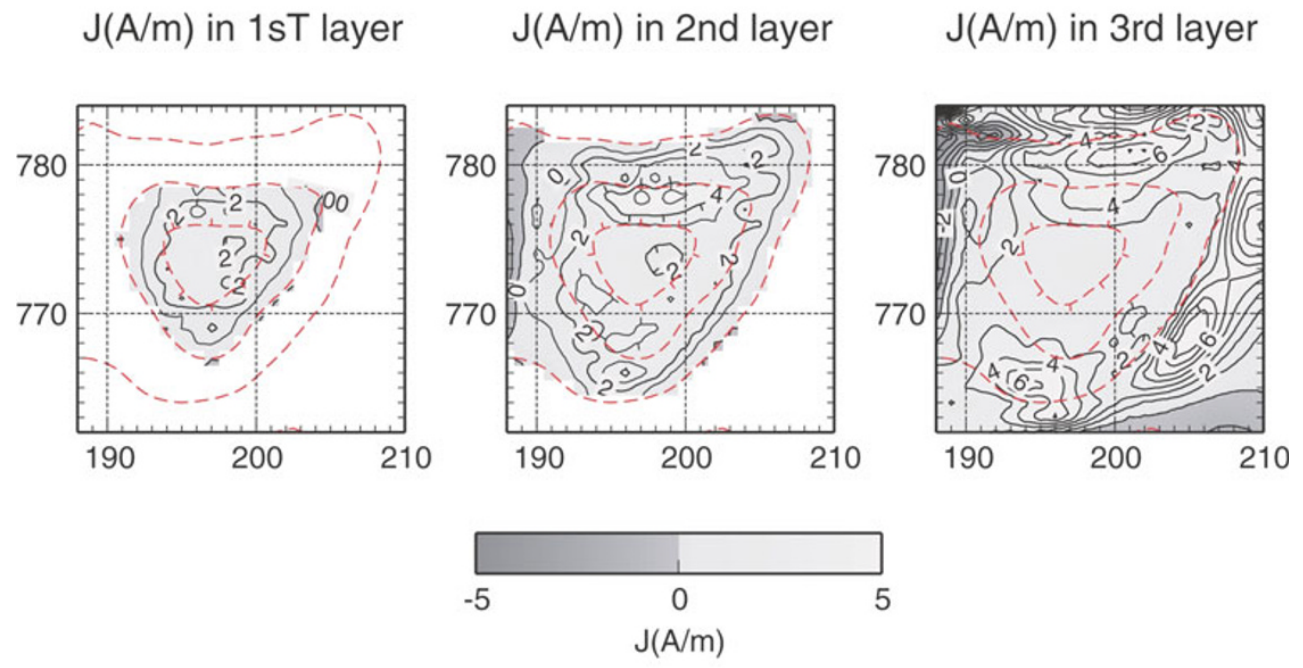

(b)

Fig. 6. 3-D-multi block modeling of Genroku seamount. (a) Topography and total force magnetic anomalies for Genroku seamount. Observed data points are shown by dot marks. Contour interval is $200 \mathrm{~m}$ in topography and $50 \mathrm{nT}$ on the magnetic anomaly map, respectively. (b) Magnetization structure of Genroku seamount derived from 3-D-multi-block modeling. Contour interval is $1 \mathrm{~A} / \mathrm{m}$. Topography is shown by broken lines at 500-m depth intervals. Left - The first layer: $0 \sim 1000 \mathrm{~m}$ in depth; middle - the second layer: 1000 1500 $\mathrm{m}$ in depth; right - the third layer: $1600 \sim 2000 \mathrm{~m}$ in depth.

tion, which is not consistent with the long period of the construction time, including several polarity reversals.

\subsection{Summary of multi-block models of the seamounts} in the Nishi-Sitito ridge

The results of the 3-D multi-block model analysis are summarized in Table 3. Among the 25 seamounts having an unusual magnetization direction in the correlation analyses, only three have a reversed magnetization part that is larger than the normally magnetized part. The unusual magnetizations in the uniform magnetization models of these seamounts (Kanei, Oki-Jyokyo, and Kouka seamounts) should be ascribed to the mixing effect of the different porality magnetizations. The magnetization intensities of these seamounts derived from the correlation analysis are generally small in magnitude. However, the majority of the seamounts $(22 / 25)$ showing unusual magnetization directions in the correlation analyses, are thought to be magnetized in the present field direction with non-uniform magnetization intensities of the edifices. In summary, the 3-D multi-block model analyses of these seamounts also clearly reveal that the majority show normal magnetizations and that the reverse magnetization parts are much smaller than those showing normal magnetization in terms of the volume rate.

\section{Discussion}

\subsection{Normal polarity bias of seamounts in the NSR}

The dredged rocks from the Nisi-Sitito ridge range from 2.2 to $15.3 \mathrm{Ma}$ in age (Yuasa and Murakami, 1985; Katsura et al., 1994; Ishizuka et al., 1998) during which time span magnetic reversals occurred frequently. However, the majority of the seamounts are magnetized in the normal direction. The seamounts in the KPR also show predominantly normal magnetizations, and no reversed seamount 
TOPO

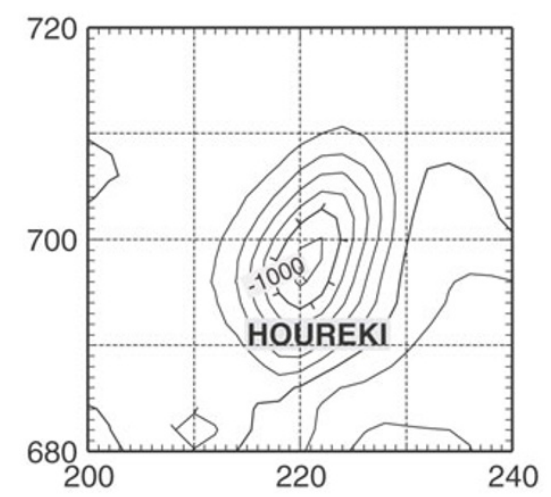

MAG

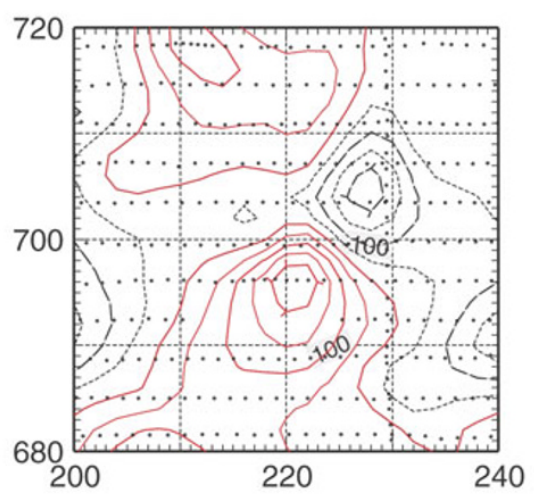

(a)

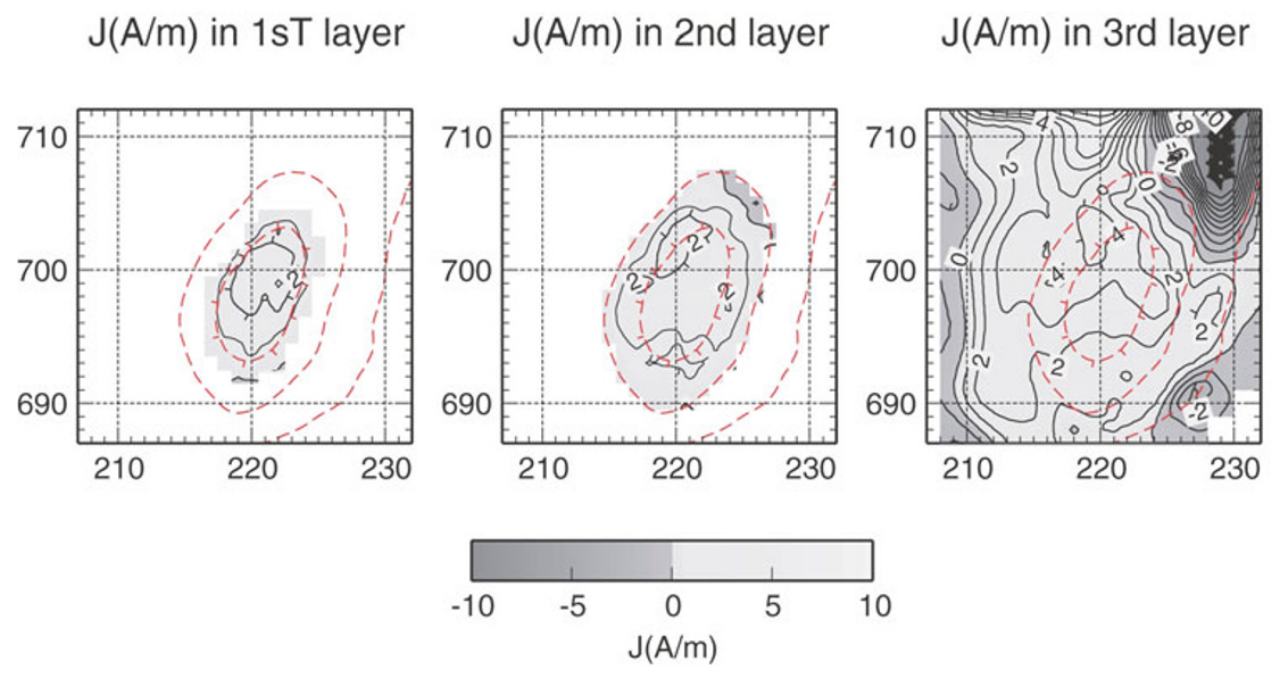

(b)

Fig. 7. 3-D-multi block modeling of Houreki seamount. (a) Topography and total force magnetic anomalies for Houreki seamount. Observed data points are shown by dot marks. Contour interval is $200 \mathrm{~m}$ in topography and $50 \mathrm{nT}$ on the magnetic anomaly map, respectively. (b) Magnetization structure of Houreki seamount derived from the 3-D-multi-block modeling. Contour interval is $1 \mathrm{~A} / \mathrm{m}$. Topography is shown by broken lines at $500-\mathrm{m}$ depth intervals. Left - The first layer: $0 \sim 1300 \mathrm{~m}$ in depth; middle - the second layer: 1300 1700 $\mathrm{m}$ in depth; Right - the third layer:1700 2100 $\mathrm{m}$ in depth.

has been discovered (Ueda, 2004). Magnetic polarity intervals in the late Oligocene to Early Miocene are also characterized by short durations. With respect to the Ryukyu arc, Ueda (1986) also found that the magnetic anomalies and topographic were predominantly in normal in terms of magnetization.

Based on the data and calculations described above, a normal polarity bias of the seamounts is indisputable for NSR and KPR. With respect of the origin of the bias towards a normal polarity, viscous magnetizations (VRM) caused by relatively large magnetic grain sizes has been proposed (Yamazaki et al., 1991; Verhoef et al., 1985; Merrill, 1985). In the following discussions, a term of induced magnetization component (IM), including total effects of VRM and IRM (induced remanent magnetization), is used in accordance with Gee et al. (1989).

\subsection{Estimation of the induced magnetization (IM) components needed for explanation of a polarity bias}

From the results shown in Tables 1 and 2, a mean magnetization intensity and standard deviation of 11 seamounts whose magnetization directions roughly coincide with the present field direction under the condition of GFR $\geqq 2.5$ are calculated as follows: $2.74 \pm 1.07 \mathrm{~A} / \mathrm{m}$ in NSR and $5.10 \pm 1.38 \mathrm{~A} / \mathrm{m}$ in SIR. The average of the seamounts in the KPR is also calculated to be $2.67 \pm 0.71 \mathrm{~A} / \mathrm{m}$. Histograms of the magnetization intensities of SIR, NSR, and the KPR are shown in Fig. 9. The mean magnetization intensity of SIR is considerably larger than that of NSR and KPR by approximately $2.4 \mathrm{~A} / \mathrm{m}$.

The geochrolological study of seamounts in NSR (Ishizuka et al., 1998) revealed a wide range of ages-from 15.3 to $2 \mathrm{Ma}$ - and several seamounts show long formation 
TOPO

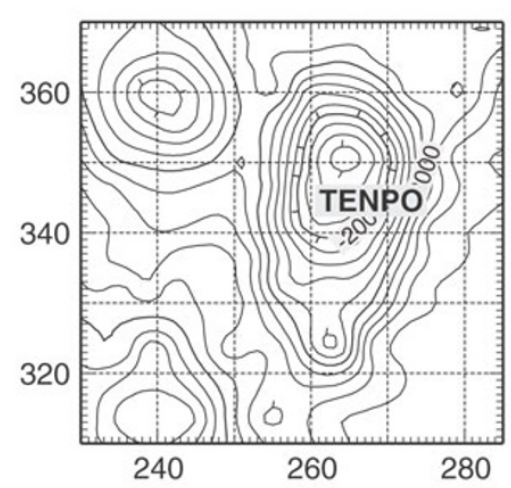

MAG

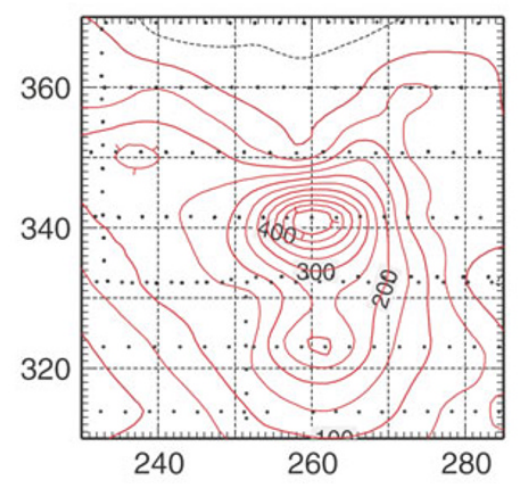

(a)
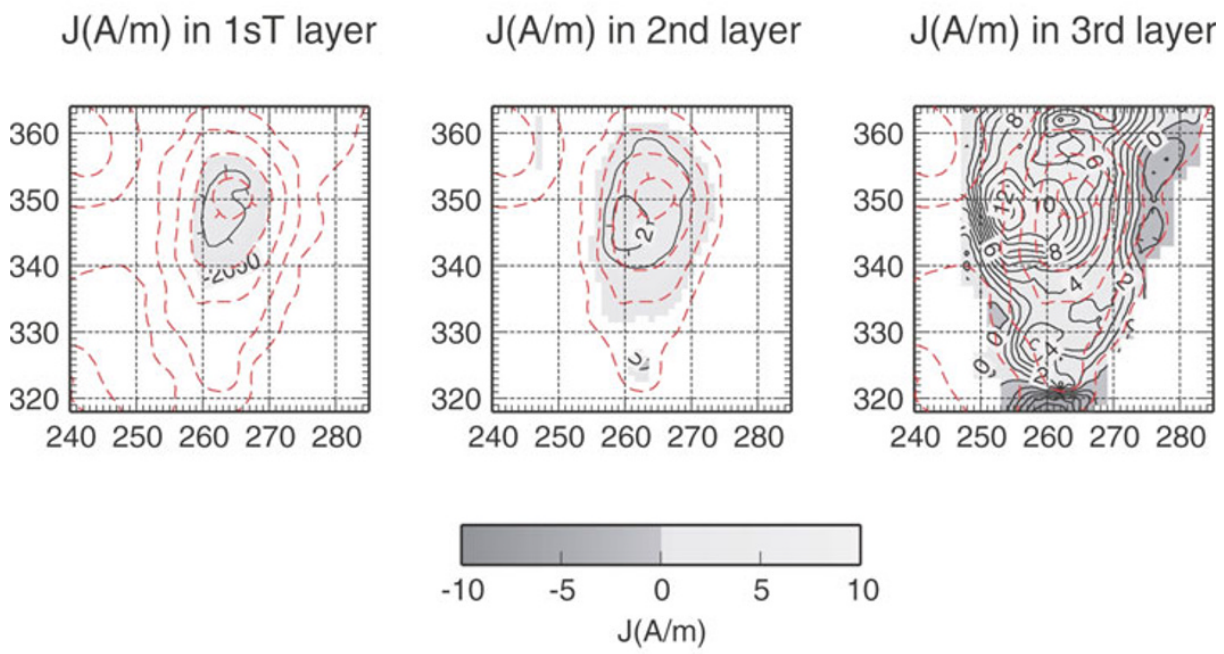

(b)

Fig. 8. 3-D-multi block modeling of Tenpo seamount. (a) Topography and total force magnetic anomalies for Tenpo seamount. Observed data points are shown by dot marks. Contour interval is $200 \mathrm{~m}$ in topography and $50 \mathrm{nT}$ on magnetic anomaly map, respectively. (b) Magnetization structure of Jyokyo seamount derived from 3-D-multi-block modeling. Contour interval is $1 \mathrm{~A} / \mathrm{m}$. Topography is shown by broken lines at each 500-m depth interval. Left - The first layer: $0 \sim 2000 \mathrm{~m}$ in depth; middle - the second layer: $2000 \sim 2700 \mathrm{~m}$ in depth; right - the third layer: $2700 \sim 3600 \mathrm{~m}$ in depth.

time spans, including several polarities. Such seamounts may show a mixing effect of magnetic polarities that cancel out the TRMs in different polarities, resulting only in IM components. If such a mixing does prevail in seamounts in NSR, calculated magnetization intensities $(1.16 \sim 4.82 \mathrm{~A} / \mathrm{m})$ of the seamounts may represent the IM components. This may be a plausible explanation for a polarity bias; however, there are a number of weak points to this proposal: (1) if a polarity mixing were to occurred during the formation of the seamounts, the magnetic anomalies associated with these seamounts should be complicated and derived values of GFR may not satisfy the condition ( $\geqq 2.5)$, however, the volumetric seamounts $\left(\geqq 250 \mathrm{~km}^{3}: 9,23,26\right)$ show smoothed dipole field patterns; (2) the correlation between the volumes and the magnetizations of the seamounts do not suggest reverse correlations (Fig. 4); (3) a majority of the sampled rocks from the seamounts do not support such large IM components (Gee et al., 1989). The mean magneti- zation intensity of the volumetric seamounts was calculated to be $3.33 \mathrm{~A} / \mathrm{m}$, which is too large to be explained by IM components.

In a relatively small seamount (volume $<150 \mathrm{~km}^{3}$ ), the formation period of a seamount is considered to be short enough to acquire a polarized TRM. In this case, the magnetization intensity should be a summation of TRM and IM. If this is the case, the magnetization intensity of the seamounts $(J)$ may be expressed by the following equation;

$$
J=b \cdot J_{N}+(1-b) \cdot J_{R}+\mathrm{IM}
$$

where $J_{N}$ and $J_{R}$ are the normally and reversely polarized TRMs, and ' $b$ ' is the volume rate of normal magnetizations. It is natural to assume $J_{N}$ and $J_{R}$ are nearly equal in magnitude with different signs (here, the normal direction is + ); therefore, the above equation can be expressed as;

$$
J=(2 b-1) \cdot \mathrm{TRM}+\mathrm{IM} .
$$


Table 3. Results of 3D-multi block modellings on the seamounts in NSR.

\begin{tabular}{|c|c|c|c|c|}
\hline ID Name & $\begin{array}{l}\mathrm{JN}^{* 1} \\
(\mathrm{~A} / \mathrm{m})\end{array}$ & $\begin{array}{l}\mathrm{JR}^{* 2} \\
(\mathrm{~A} / \mathrm{m})\end{array}$ & $\begin{array}{c}\text { Volume rate } \\
\text { of normal }\end{array}$ & $\begin{array}{c}\text { base depth } \\
\text { (m) }\end{array}$ \\
\hline 2 Genna & 1.40 & 2.92 & 82.9 & 2800 \\
\hline 3 Kanei & 0.35 & 1.01 & 37.7 & 1700 \\
\hline 4 Nishi-seiho & 3.74 & 0.83 & 96.7 & 3800 \\
\hline 5 Seiho & 1.03 & 0.37 & 68.2 & 3000 \\
\hline 10Kita-jyokyo & 1.21 & 1.63 & 61.3 & 4000 \\
\hline 12 Ten'na & 3.28 & 2.11 & 95.2 & 2700 \\
\hline 13 Jyokyo & 2.38 & 1.40 & 53.1 & 3000 \\
\hline 14 Nishi-Jyokyo & 1.22 & 0.84 & 61.7 & 3000 \\
\hline 15 Oki-Jyokyo & 0.69 & 2.06 & 49.7 & 4000 \\
\hline 16 Genroku & 2.90 & 2.56 & 93.7 & 2000 \\
\hline 17 Houei & 2.83 & 0.71 & 98.8 & 2500 \\
\hline 18 Syotoku & 1.83 & 0.82 & 97.5 & 3000 \\
\hline 22 Houreki & 2.17 & 3.53 & 89.1 & 2100 \\
\hline 25 Kanen & 0.89 & 1.25 & 53.4 & 3500 \\
\hline 27 Anei & 1.81 & 0.69 & 92.4 & 3400 \\
\hline 28 Kansei & 1.99 & 1.33 & 60.5 & 4000 \\
\hline 29 Minami-anei & 3.29 & 1.10 & 95.4 & 3600 \\
\hline 31 Kyouwa & 1.47 & 0.92 & 78.2 & 3800 \\
\hline 32 Bunka & 2.89 & 3.19 & 85.1 & 4000 \\
\hline 33 Bunsei & 5.24 & 1.24 & 97.6 & 3800 \\
\hline 34 Nishi-tenpo & 3.16 & 1.36 & 99.3 & 3500 \\
\hline 35 Tenpo & 4.35 & 1.52 & 94.1 & 3600 \\
\hline 36 Kouka & 0.81 & 0.77 & 44.9 & 4800 \\
\hline 37 Nishi-Kaitoku & 4.43 & 1.77 & 89.0 & 3800 \\
\hline 38 unnamed & 3.22 & 3.05 & 85.5 & 3900 \\
\hline
\end{tabular}

In Eq. (6), a perfect mixing is the case of $b=0.5$, and the normally magnetized case is $b=1$. This means that the magnetization intensities of small seamounts scatter over a wide range between the absolute of -TRM + IM (reverse magnetization) and TRM + IM (normal magnetization); however, such a trend is not recognized in Fig. 4, which may reflect a small contribution of IM. A mean magnetization intensity of normally magnetized seamounts in NSR is calculated to be $2.87 \pm 1.17 \mathrm{~A} / \mathrm{m}$, and the reversed one is $1.65 \mathrm{~A} / \mathrm{m}$ (only one seamount: 30 ); consequently, an IM component is estimated to be $0.61 \mathrm{~A} / \mathrm{m}$. In this case, a mean TRM should be $2.26 \mathrm{~A} / \mathrm{m}$ for the seamounts in NSR. As to the origin of the significant difference in the mean magnetization intensities between the seamounts in NSR and SIR, a mixing effect of different polarities of the seamounts in NSR may be plausible; however, as the condition of complete mixing ( $b=0.5$ ) is not supported, as already discussed (Fig. 4), we should assume a moderate mixing case $(b \neq 0.5)$. The net magnetization intensities may then show bimodal histograms with peaks at $-0.4 \cdot \mathrm{TRM}+\mathrm{IM}(b=0.3$, reversed magnetization $)$ and $0.4 \cdot$ TRM + IM ( $b=0.7$, normal magnetization), if the volcanism forming the edifice of the seamount occurred at the same probability during the normal and reverse period.
This case results in larger standard deviations in the statistics of the magnetizations; however, we can not recognize a significant difference between standard deviations in the statistics of magnetization intensities, suggesting small contributions of IM. As described above, the difference may be ascribed to lithological differences among these seamounts: andesitic to basaltic rocks in the western part of the NSR and mainly basaltic rocks in the SIR (Ishizuka et al., 1998).

\subsection{Estimation of IM components based on the results} by multi-block modeling

If seamounts consist of two TRMs polarized in the normal and reverse directions, a mean magnetization intensity of the normally polarized one should be greater than that of the reversely polarized one by as much as twice the IM. If we refer to the results by multi-block modeling (Table 3), 17 seamounts satisfy the above condition. The mean differences between normal and reverse magnetizations are calculated to be $1.42 \pm 1.13 \mathrm{~A} / \mathrm{m}$; therefore, the estimated IM should have the value of $0.71 \pm 0.57 \mathrm{~A} / \mathrm{m}$. This value is consistent with the estimated IM value of $0.72 \mathrm{~A} / \mathrm{m}$ derived in the former section and also with the calculated value from seamounts in the Pacific basin.

\subsection{Evaluation of IM components by other sources}

Hildebrand and Staudigel (1986) indicated that the net amount of IM should not exceed $25 \%$ of the NRM based on a comparative study of Pacific seamount magnetizations having normal and reverse polarity. Using data of the magnetizations of Pacific seamounts compiled by Sager (1992), a mean magnetization intensity of seamounts having normal polarities is calculated to be $6.19 \pm 3.02 \mathrm{~A} / \mathrm{m}$ and that of reverse polarities becomes $4.26 \pm 2.05 \mathrm{~A} / \mathrm{m}$. This result suggests that these mean magnetization intensities can be distinguished at the $90 \%$ confidence level, which may enable us to estimate the IM contribution to be as high as $1.0 \mathrm{~A} / \mathrm{m}$ - about $20 \%$ of the normal magnetization component.

Gee et al. (1989) showed that the seamounts with average densities greater than $2.70 \mathrm{~g} / \mathrm{cm}^{3}$ contain a significant portion of plutonic rocks and exhibit a large IM contribution. Referring to the gravity anomalies, the closed contour lines of free-air anomalies corresponding to seamounts in the NSR and KPR are considerably subdued in the Bouguer gravity anomalies at an assumed density of $2.67 \mathrm{~g} / \mathrm{cm}^{3}$ (Ueda, 2005). This feature may imply that the mean densities of the seamounts in NSR and KPR are generally comparable to the assumed density $\left(2.67 \mathrm{~g} / \mathrm{cm}^{3}\right)$. The calculated densities are also listed in the right column of Tables 1 and 2 . Five seamounts satisfy the condition $(\rho \geqq 2.7)$, but this number is quite small compared to the total number of seamounts in the NSR (4/38). Judging from these results, the presence of IM components due to intrusives would appear to be rare in the NSR.

Higher temperature conditions inside seamounts may also produce large contributions of the IM components. This may be a plausible explanation in the volcanic frontal seamounts, where subsurface temperatures become high due to heat sources of magmas. In the case of the seamount in KPR older than approximately $25 \mathrm{Ma}$, it is not reasonable to assure such a high temperature conditions, although they also display a polarity bias. However, this explanation 


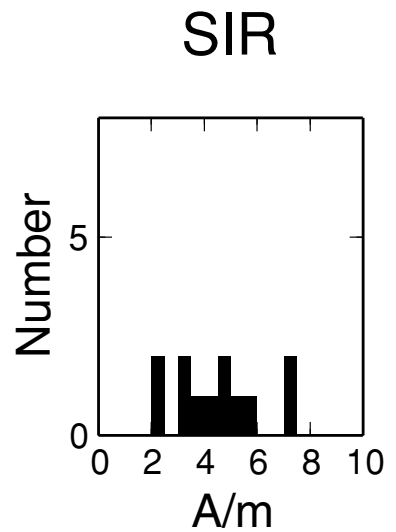

SIR

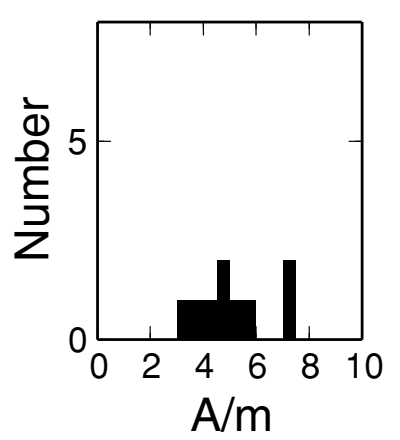

NSR

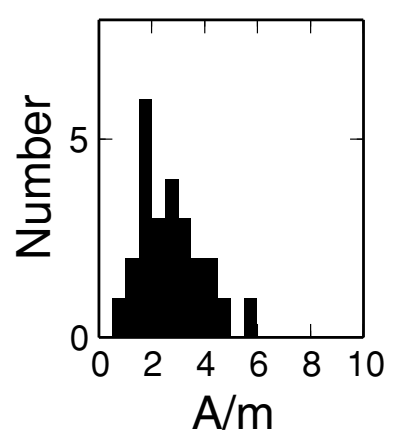

NSR

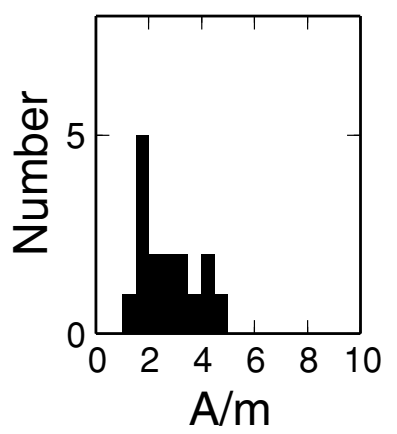

KPR

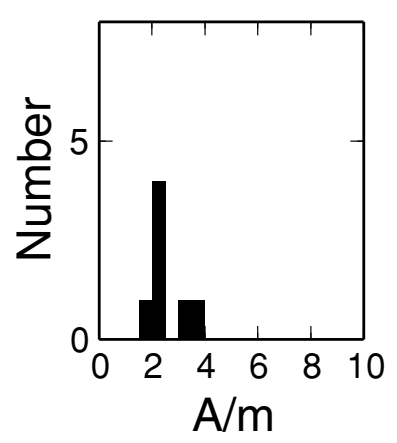

KPR

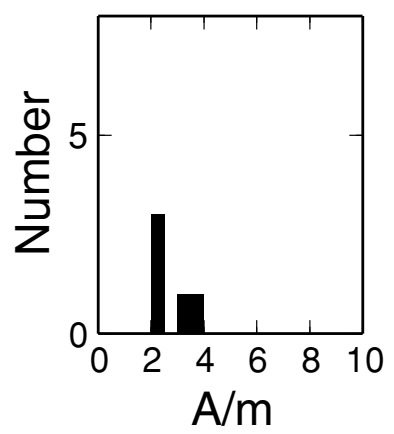

Fig. 9. Histograms of magnetization intensities of seamounts in SIR, NSR and KPR, respectively. Upper: Results satisfying the condition of GFR $\geqq 2.0$ Lower: Results satisfying the condition of GFR $\geqq 2.5$.

may be plausible in the seamounts of the NSR at a distance about 100 to approximately $180 \mathrm{~km}$ west of the present volcanic front; however, no observations confirm hydrothermal activity on the seamounts in NSR. Concerning to this issue, sea bottom observations of the seamounts in NSR and their drilling cores are needed for more critical discussions.

As already discussed, in order to accept an IM origin of normal polarity bias, the magnitude of the IM components must be greater than $2.7 \sim 3.3 \mathrm{~A} / \mathrm{m}$. However, present studies show this value to be about $0.6 \mathrm{~A} / \mathrm{m}$, which is too small to explain the polarity bias by the IM origin. An alternative origin of the polarity bias may be ascribed to enhanced arc volcanisms in the normal period. A theoretical background supporting this speculation has not yet been proposed, however, it seems natural to assume that the Earth's magnetic dipole in parallel or anti-parallel to the Earth's rotational vector may cause different effects to the thermal convection in the core, which in turn may result in the observed polarity bias. In the equations of magnetohydro-dynamics (MHD), both $\mathbf{B}$ and $-\mathbf{B}$ satisfy the MHD equation on the condition that a displacement current is negligible. In the real Earth situation, such an approximation may not hold true, resulting in different solutions in $\mathbf{B}$ and $-\mathbf{B}$. If MHD solutions in the case of $\mathbf{B}$ and $-\mathbf{B}$ give the same solution, it is difficult to understand why a long reverse magnetic field period comparable to the Cretaceous normal superchron does not exist. Although geodynamo theory has been developed to a considerable degree, we should recognize that it still does not enable us to carry out perfect simulations of magnetic reversals.

\section{Conclusion}

The correlation analyses of seamounts in the IzuOgasawara ridge and KPR show a normal polarity bias. With respect to the Izu-Ogasawara arc, the seamounts in the NSR were almost all normally magnetized (92\%: 11/12). No reverse magnetizations were found for the seamounts in the KPR. These results support the proposal that the normal polarity bias is not an artifact but a real phenomenon. An IM origin for the normal polarity bias is examined using averages and standard deviations of magnetization intensities of seamounts. The results indicate that there is no appreciable difference in the standard deviations of the seamounts in NSR and SIR.

Twenty-five seamounts in the NSR having unusual magnetization directions are analyzed by a 3-D multi-block model. Among them, 16 seamounts can be approximated by the normal magnetization blocks with non-uniform magnetization intensities, while the other nine seamounts show a mixing of the different polarity magnetization of the edifices, ranging from 37.7 to $68.2 \%$ in the volume of normal polarity. In the latter case, three seamounts have a reverse magnetization part larger than that of the normal magnetization in terms of volume. If these seamounts are considered 
to be reversely magnetized seamounts, the normal polarity bias becomes $31 / 35(89 \%)$, where three seamounts $(8,11$, 19) are excluded due to uncertainties of these polarities. As described above, the normal polarity bias of the seamounts in NSR can not be denied. The IM component inferred from the results of the 3-D-multi-block model (Table 3) becomes $0.66 \mathrm{~A} / \mathrm{m}$ in the largest estimation, which also fails to explain the observed normal polarity bias. An alternative to the IM origin of the normal polarity bias may be enhanced arc volcanic activity during normal magnetic periods. Otherwise, the IM contribution, especially VRM, should be large enough to cancel reversely magnetized TRM amounting to $2.7 \sim 3.3 \mathrm{~A} / \mathrm{m}$. At the present stage, the latter origin fails to explain the normal polarity bias, as discussed.

Acknowledgments. Author would like to express his heartfelt thanks to JODC of the Japanese Hydrographic and Oceanographic Department for providing the MGD77 data for the present study. He is also grateful to Dr. W. W. Sager for his critical reading of the manuscript and constructive comments, including language corrections, and gratefully acknowledges another anonymous reviewer for his critical suggestions for improving manuscripts. GMT mapping software was used to make the figures (Wessel and Smith, 1995).

\section{References}

Bjorck, A. and T., Elfving, Accelarated projection methods for computing pseudoinverse solutions of systems of linear equations, BIT, 19, 145$163,1979$.

Francheteau, J., C. G. A. Harrison, J. G. Sclater, and M. G. Richards, Magnetization of Pacific seamounts: a preliminary polar curve for the northeastern Pacific, J. Geophys. Res., 75, 2035-2061, 1970.

Gee, J., L. Tauxe, J. A. Hildebrand, H. Staudigel, and P. Lonsdale, Nonuniform magnetization of Jasper seamount, J. Geophys. Res., 93, 1215912175,1988

Gee, J., H. Staudigel, and L. Tauce, Contribution of induced magnetization to magnetization of seamounts, Nature, 342, 170-173, 1989.

Grauch, V. J. S., A new variable-magnetization terrain correction method for aeromagnetic data, Geophysics, 52, 94-107, 1987.

Harrison, C. G. A., R. D. Jarrard, V. Vacquier, and L. Larson, Paleomagnetism of Cretaceous Pacific seamounts, Geophys. J. R. Astron. Soc., 42, 859-882, 1975.

Hildebrand, J. A. and H. Staudigel, Seamount magnetic polarity and Cretaceous volcanism of the Pacific basin, Geology, 14, 456-458, 1986.

Ishizuka, O., K. Uto, M. Yuasa, and A. G. Hochstaedter, K-Ar ages from seamount chains in the back-arc region of the Izu-Ogasawara arc, The Island Arc, 7, 408-421, 1998.

Kasuga, S., M. Hayashida, and collaborators in continental shelf surveys office, Publication of geomagnetic and gravity anomaly chart and characteristics of the magnetic anomalies in the southern waters of Japan, Hydrogr. Res. Rep., 30, 329-344, 1994 (in Japanese with English abstract).

Katsura, T., K. Shimamura, and collaborators in continental shelf survey office, Geological, geochemical researches of bottom samples, from continental shelf surveys, H.D.Japan(part1)-preliminary study for ocean floor on the Japanese continental shelves, Hydrogr. Res. Rep., 30, 345381, 1994 (in Japanese with English abstract).

Merrill, R. T., Correlating magnetic field polarity changes with geologic phenomena, Geology, 13, 487-490, 1985.

Moberly, R. and J. F. Cambell, Hawaiian hotspot volcanism mainly during geomagnetic normal intervals, Geology, 12, 459-463, 1984.

Nakamura, K., Preliminary estimate of global volcanic production rate, proceeding of a United States-Japan cooperative science seminar of the utilization of volcanic energy, 680 pp., edited by J. L. Colp and A. S. Furumoto, University of Hawaii, 273-285, 1974.

Okino, K., Y. Shimakawa, and S. Nagaoka, Evolution of the Shikoku Basin, J. Geomag. Geoelectr., 46, 463-479, 1994.

Richard, J. B., Potential theory in gravity and magnetic applications, Cambridge University Press, 1-441, 1995.

Sager, W. W., Late Eocene and Maastrichtian paleomagnetic poles for the Pacific plate:implications for the validity of seamount paleomagnetic data, Tectonophysics, 144, 301-314, 1987.

Sager, W. W., Seamount age estimates from paleomagnetism and their implications for the history of volcanism on the Pacific plate, in Geology and offshore mineral resources of the central Pacific basin, CircumPacific Council for Energy and Mineral Resources Earth Science Ser. 14, edited by B. H. Keating and B. R. Bolton, pp. 21-37, SpringerVerlag, New York, 1992.

Shukuno, H., O. Ishizuka, Y. Tamura, K. Tami, and H. Kawabata, Olivine-spinel compositional relationships of Horeki basalts from IzuOgasawara arc, 170 p., 2006 (Programme and abstracts the volcanological society of Japan, 2006 fall meeting).

Smith, W. H. F. and P. Wessel, Gridding with continuous curvature spline intension, Geophysics, 55, 293-305, 1990.

Tarduno, J. A., R. A. Duncan, D. W. Scholl, R. D. Cottrell, B. Steinberger, T. Thordarson, B. C. Kerr, C. R. Near, F. A. Frey, M. Torii, and C. Carvallo, The Emperor Seamounts: southward motion of the Hawaiian hotspot plume in the Earth's mantle, Science, 301, 1064-1069, 2003.

Tomoda, Y., K. Kobayashi, J. Segawa, M. Nomura, K. Kimura, and T. Saki, Linear magnetic anomalies in the Shikoku Basin,northwestern Philippine Sea, J. Geomag. Geoelectr., 27, 47-56, 1975.

Tunakawa, H., K-Ar dating of volcanic rocks in the Bonin Islands and its tectonic implications, Tectonophysics, 95, 221-232, 1983.

Ueda, Y., Geomagnetic anomaies around the Nansei Syoto (Ryukyu Islands) and their tectonic implications, Bull. Volcanol. Soc. Jpn., 31, 177 192, 1986 (in Japanese with English abstract).

Ueda, Y., Magnetic and gravity field analyses of Izu-Ogasawara (Bonin) arc and their tectonic implications, J. Geomag. Geoelectr., 48, 421-445, 1996.

Ueda, Y., Paleomagnetism of seamounts in the west Philippine sea as inferred from correlation analysis of magnetic anomalies, Earth Planets Space, 56, 967-977, 2004.

Ueda, Y., Bouguer gravity anomalies (ver.2004) of Japanese Island arcs and its adjacent seas, Rept. Hydro. Oceanogr. Res., 41, 1-26, 2005 (in Japanese with English abstract).

Ueda, Y., 3D magnetic structure of Miyakejima Volcano before and after the eruption in 2000, Bull. Volcanolo. Soc. of Japan, 51, 161-174, 2006 (in Japanese with English abstract).

Uyeda, S. and M. L. Richards, Magnetization of four Pacific seamounts near the Japanese Islands, Bull. Earthq. Res. Inst., 44, 179-213, 1966.

Verhoef, J., B. J. Collette, and C. A. Williams, Comment and reply on "Hawaiian hotspot volcanism mainly during geomagnetic normal intervals", Geology, 13, 314-315, 1985.

Wessel, P. and W. H. F. Smith, New version of the Generic mapping tools released, EOS Trans. AGU, 76, 329, 1995

Yamazaki, T., T. Ishihara, and F. Murakami, Magnetic anomalies over the Izu-Ogasawara (Bonin) Arc, Mariana Arc and Mariana Trough, Bull. Geol. Surv. Jpn., 42, 655-686, 1991.

Yuasa, M. and F. Murakami, Geology and geomorphology of the Ogasawara arc and the Sofugan tectonic line, J. Geogr., 94, 47-66, 1985 (in Japanese with English abstract).

Y. Ueda (e-mail: yueda10@hotmail.com) 